\title{
Apoptosis of limb innervating motor neurons and erosion of motor pool identity upon lineage specific Dicer inactivation
}

\author{
Jun-An Chen $^{1,2 *}$ and Hynek Wichterle ${ }^{1 *}$ \\ 1 Departments of Pathology and Cell Biology, Neurology, and Neuroscience, Center for Motor Neuron Biology and Disease, Columbia University Medical Center, \\ New York, NY, USA \\ 2 Institute of Molecular Biology, Academia Sinica, Taipei, Taiwan
}

\author{
Edited by: \\ Yanhong Shi, City of Hope, USA \\ Reviewed by: \\ Benedikt Berninger, \\ Ludwig-Maximilians-Universität \\ München, Germany \\ Gonzalo Alvarez-Bolado, University of \\ Heidelberg, Germany \\ *Correspondence: \\ Jun-An Chen, N520, Institute of \\ Molecular Biology, Academia Sinica, \\ 128 Academia Road, Section 2, \\ Nankang, Taipei 11529, Taiwan. \\ e-mail: jachen@imb.sinica.edu.tw; \\ Hynek Wichterle, P\&S 14-401G, \\ 630W, 168th Street, New York, \\ NY 10032, USA. \\ e-mail: hw350@columbia.edu
}

\begin{abstract}
Diversification of mammalian spinal motor neurons into hundreds of subtypes is critical for the maintenance of body posture and coordination of complex movements. Motor neuron differentiation is controlled by extrinsic signals that regulate intrinsic genetic programs specifying and consolidating motor neuron subtype identity. While transcription factors have been recognized as principal regulators of the intrinsic program, the role of posttranscriptional regulations has not been systematically tested. MicroRNAs produced by Dicer mediated cleavage of RNA hairpins contribute to gene regulation by posttranscriptional silencing. Here we used Olig2-cre conditional deletion of Dicer gene in motor neuron progenitors to examine effects of miRNA biogenesis disruption on postmitotic spinal motor neurons. We report that despite the initial increase in the number of motor neuron progenitors, disruption of Dicer function results in a loss of many limb- and sympathetic ganglia-innervating spinal motor neurons. Furthermore, it leads to defects in motor pool identity specification. Thus, our results indicate that miRNAs are an integral part of the genetic program controlling motor neuron survival and acquisition of subtype specific properties.
\end{abstract}

Keywords: microRNA, motor neurons, Dicer, spinal cord, motor neuron subtype, motor pool, oligodendrocyte, astrocyte

\section{INTRODUCTION}

The execution of body movement relies on the precise point-topoint connections between motor neurons and their peripheral muscle targets. This organization is most prominent at limb levels where motor neurons supplying limb muscles found in the lateral motor column (LMC) are subdivided into molecularly identifiable motor pools innervating individual muscle groups in the limbs (Dasen, 2009). Diversification of motor neurons to individual subtypes is principally controlled by the Hox family of homeodomain containing transcription factors (TFs; Dasen et al., 2003). Combinatorial code of these factors regulates rostro-caudally restricted expression of LMC determinant FoxP1 in brachial and lumbar spinal cord (Dasen et al., 2008). In addition to LMC neurons, FoxP1 is expressed at low levels in preganglionic column (PGC) motor neurons located in the thoracic spinal cord. In the absence of FoxP1, both LMC and PGC neurons acquire identity of motor neurons innervating hypaxial (HMC) and to lesser extent axial (MMC) muscles (Dasen et al., 2008; Rousso et al., 2008). Conversely, overexpression of FoxP1 results in the conversion of PGC neurons to LMC like identity, revealing concentration dependent role of FoxP1 in specification of motor neuron columnar identity.

While TFs were identified as the primary determinants of generic and subtype motor neuron identity (Briscoe et al., 2000;
Dasen et al., 2003, 2005, 2008), several studies also demonstrated that microRNA mediated posttranscriptional regulation participates in fine-tuning the program of motor neuron progenitor specification (Chen et al., 2011), motor neuron differentiation (Cao et al., 2007; Visvanathan et al., 2007), and subtype diversification (Otaegi et al., 2011a). Notably, a recent study revealed that LMC determinant FoxP1 is co-expressed and negatively regulated by a small RNA mir-9. The ability of mir-9 to regulate motor neuron subtype identity has been demonstrated in an overexpression study that resulted in a reduction of LMC and increase in MMC motor neurons (Otaegi et al., 2011a,b), suggesting that miRNAs might be involved in the fine-tuning process of motor neuron subtype identity specification.

To investigate whether miRNAs are more globally involved in the regulation of postmitotic motor neurons, we performed a detail analysis of motor neuron subtype phenotype in mice in which Dicer enzyme is conditionally deleted in all motor neuron progenitors. Our findings indicate that LMC and PGC neurons are selectively sensitive to the disruption of miRNA biogenesis, while MMC and HMC motor neurons appear unaffected. Our results provide evidence that miRNAs together with TFs are critical for the maintenance of motor neurons and for motor pool specification in the developing spinal cord. 


\section{MATERIALS AND METHODS MOUSE CROSSES AND IN VIVO STUDIES}

The recombination efficiency and specificity of $\mathrm{Olig} 2 \mathrm{Cre} /+$ mice (Dessaud et al., 2007; Chen et al., 2011) were assessed by crossing them to the reporter mice ROSA26-loxp-STOP-loxp-YFP mice (Srinivas et al., 2001) and resulting embryos were analyzed at E13.5.

Olig2 Cre/t mice were crossed with Dicerflox/flox (Harfe et al., 2005) to generate Olig2 ${ }^{\mathrm{Cre} /+}$; Dicer ${ }^{\text {flox/WT }}$ strain. Olig2 $2^{\mathrm{Cre} /+}$; Dicerflox/WT mice were then mated with either Dicerflox/flox or Hb9::GFP;Dicerflox/flox for experimental analysis. Embryos were analyzed at E11.5-E16.5. All mice were maintained in C57BL/6 background. All experiments were performed according to the approved Columbia University IACUC protocols.

\section{IMMUNOSTAINING AND ANTIBODIES}

Antibodies used in this study include: rabbit anti-mouse Olig2 (Millipore, AB9610), guinea pig anti-mouse Olig2, mouse antiLhx3 and Hb9, guinea pig anti-Isl1, FoxP1, and SCIP (gift from Tom Jessell), rabbit anti-Sox9 and GFAP, rabbit anti-pSmad (gift from Ed Laufer), mouse anti-Hoxc8 (gift from Tom Jessell), goat anti-Hoxc6 (Santa Cruz, sc-66925), and Alexa488-, FITC, Cy3-, and Cy5-conjugated secondary antibodies were obtained from either Invitrogen or Jackson Immunoresearch. Images were collected on a Zeiss LSM510 confocal microscope.

\section{MIRNA IN SITU HYBRIDIZATION}

In situ hybridizations were performed in $15 \mu \mathrm{m}$ cryosections from E13.5 brachial spinal cord. Sections were fixed in $4 \%$ paraformaldehyde and acetylated in acetic anhydride/triethanolamine, followed by washes in PBS. Sections were then pre-hybridized in hybridization solution (50\% formamide, $5 \times$ SSC, $0.5 \mathrm{mg} / \mathrm{mL}$ yeast tRNA, $1 \times$ Denhardt's solution) at room temperature, then hybridized with $3^{\prime}$-DIG labeled LNA probes ( 3 pmol; LNA miRCURY probe; Exiqon) at $25^{\circ} \mathrm{C}$ below the predicted $T_{\mathrm{m}}$ value. After post-hybridization washes in $0.2 \times \mathrm{SSC}$ at $55^{\circ} \mathrm{C}$, the in situ hybridization signals were detected using the NBT/BCIP (Roche) according to the manufacturer's instructions. Slides were mounted in Aqua-Poly/Mount (Polysciences, Inc.) and analyzed with a Zeiss LSM 510 confocal microscope. Detail protocols can be checked from Chen et al. (2005, 2007, 2011).

\section{RESULTS}

\section{EFFICIENT DISRUPTION OF MIRNA BIOGENESIS IN MOTOR NEURONS AND OLIGODENDROCYTE PRECURSORS IN Olig2 ${ }^{\text {Cre/++}}$; Dicer ${ }^{\text {flox/flox }}$ EMBRYOS}

Motor neuron differentiation is driven by a transcriptional program that diversifies generic motor neurons into hundreds of distinct subtypes along the rostro-caudal axis of the spinal cord (Dasen, 2009). To investigate if miRNAs are involved in this process, we took advantage of Olig $2^{\mathrm{Cre} /+}$ mouse line that expresses Cre recombinase in progenitors of all spinal motor neurons and oligodendrocytes (Dessaud et al., 2007). To confirm efficiency of recombination we crossed the Olig2 ${ }^{\text {Cre/ }+}$ mouse to ROSA26loxp-STOP-loxp-YFP reporter mouse in which all cells derived from Olig2 positive progenitors should be labeled by YFP expression. Consistent with previous studies (Masahira et al., 2006), we

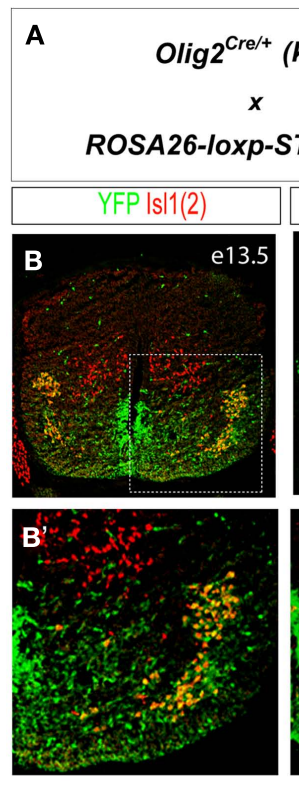

knock-in allele) -STOP-IOXP-YFP
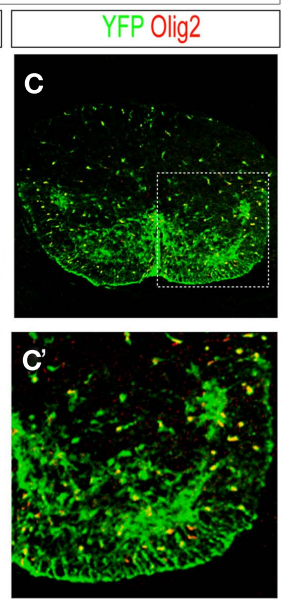

FIGURE 1 | Efficient and specific disruption miRNA biosynthesis in Olig2 $2^{\text {Cre/+ }}$; Dicer flox/flox animals. (A) Schematic illustration of Olig2-Crelineage tracing (YFPon cells) in Olig2 ${ }^{\mathrm{Cre} / \mathrm{t}}$; ROSA26-loxp-STOP-loxp-YFP E13.5 spinal cord sections. (B,C) Cre mediated recombination in Olig2 expressing progenitors results in YFP expression in all cells derived from this progenitor domain. YFP is expressed in all postmitotic motor neurons in the ventral horn of the spinal cord (YFPon and IsI1 ${ }^{\text {on }}$ ), but not in dorsal dl3 interneurons

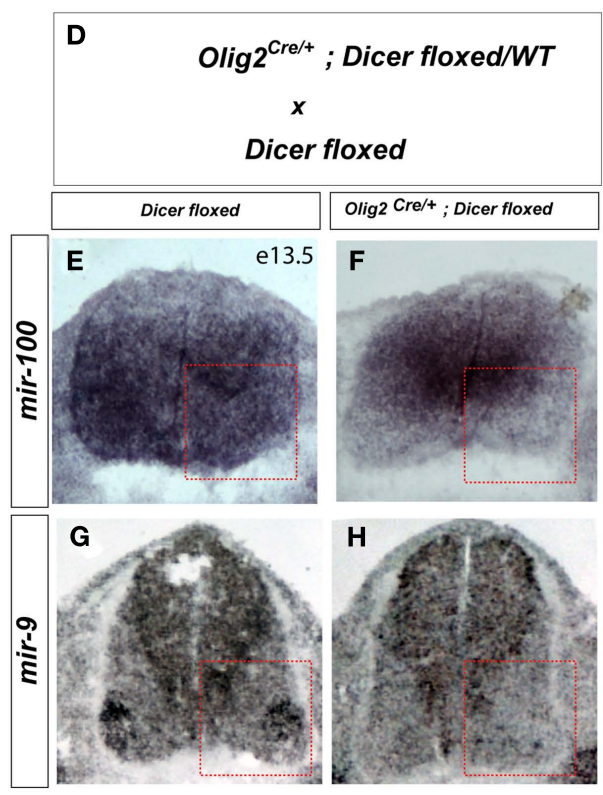

(YFPoff and Is $\mid 1^{\text {on }}$ ). In addition, nearly all Olig2 ${ }^{+}$oligodendrocyte precursors express the lineage tracer YFP. (D) Cross between Olig2 ${ }^{\text {Cre/t }}$; Dicer ${ }^{\text {floxWT }}$; and Dicerfloxflox female mouse to get control wild type (WT) and conditional Dicer knock out (conditional KO) embryos. (E-H) Spinal cord sections from E13.5 WT and conditional KO embryos examined for miR-100 and mir-9 expression by in situ hybridization. Ventral horn is marked by the dashed square. 
observed that all motor neurons and oligodendrocyte precursors (OPCs) on day 13.5 of development (E13.5) are marked by YFP expression demonstrating that they are derived from Olig2 expressing spinal progenitors (pMN; Figures 1A-C).

Next we examined the efficiency of Dicer deletion in $\mathrm{pMN}$ lineage in Olig2 ${ }^{\mathrm{Cre} /+}$; Dicerflox/flox mice (Figures 1A-C). In situ hybridization using a locked nucleic acid (LNA) probe revealed depletion of a neuronal enriched miRNA mir-100 in the ventral horn of the spinal cord as well as depletion of mir-9 enriched in postmitotic motor neuron, indicating loss of miRNAs in postmitotic motor neurons (Figures 1D-H).

Because deletion of Dicer function in early neural progenitors results in dorso-ventral patterning defect (Chen et al., 2011), we examined whether decreased levels of miRNAs in motor neuron progenitors affect spinal cord patterning or motor neuron production. Consistent with previous report (Zheng et al., 2010), we did not detect any changes in the position of dorso-ventral boundaries marked by Olig2, Nkx2.2, and Irx3 expression in E10.5 spinal cord and observed comparable number of $\mathrm{Hb}^{\text {on }}$ and Isl $1^{\text {on }}$ motor neurons generated in conditional KO and WT E11.5 embryos (data not shown and Figures 2A-E).

Previously it has been shown that oligodendrocyte differentiation is impaired in Olig1-Cre $e^{+/-}$; Dicer ${ }^{\text {flox/flox }}$ mutants (Dugas et al., 2010). Staining E16.5 spinal cords of Olig2 $2^{\mathrm{Cre} /+}$; Dicerflox/flox mutant mice for oligodendroglial and astrocytic markers revealed nearly complete loss of oligodendroglial progenitor cells expressing Olig2 and Sox9 whereas astroglial cells (GFAP ${ }^{\text {on }}$, Olig2 ${ }^{\text {off }}$, Sox $\left.9^{\text {on }}\right)$ remained unaffected $(N=3$, Figures $2 \mathbf{F}-\mathbf{H})$. Taken together, our data are consistent with previous results, and indicate efficient deletion of Dicer function and loss of miRNAs in motor neuron and oligodendroglial lineages in the Olig2 ${ }^{\text {Cre/ }}+$ Dicerflox/flox mutants.

\section{DIFFERENTIAL EFFECT OF MIRNA DEPLETION ON MOTOR NEURON COLUMNS}

Postmitotic motor neurons acquire diverse subtype identities and settle into distinct motor columns in the developing spinal cord (Figure 3A). We therefore inspected pattern of expression of
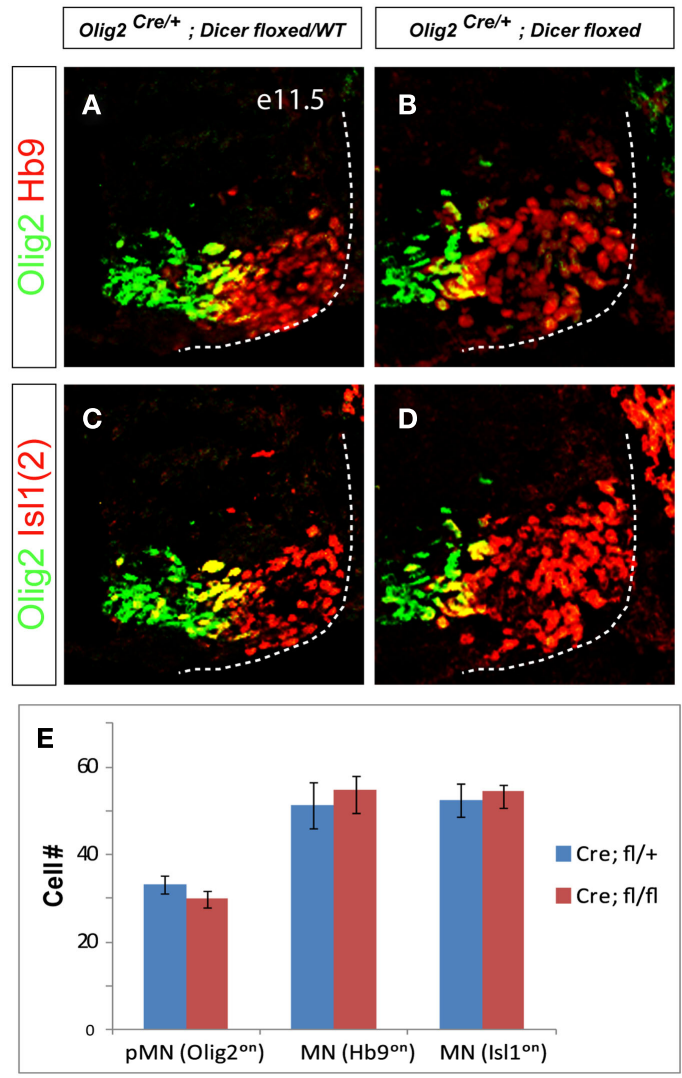

FIGURE 2 | Conditional deletion of Dicer results in the loss of oligodendrocyte progenitors, but normal production of astrocytes and motor neuron progenitors. (A-D) Specification of pMN (Olig2 ${ }^{\circ}$ ) progenitors and generic motor neurons (ISI1 on or $\mathrm{Hbg}^{\circ \mathrm{n}}$ ) are not affected in Olig2 $2^{\mathrm{Cre} / \mathrm{t}}$; Dicer flox/flox spinal cord at E11.5. (E) Quantification of ventral pMN and postmitotic motor neurons (MNs; number of positive cells per $15 \mu \mathrm{m}$ brachial spinal cord hemisection) in WT and conditional KO embryos (mean $\pm \mathrm{SD}$ ) reveals a comparable cell number of pMN progenitors and generic motor neurons $(N=3$ embryos at $E 11.5)$. (F,G)
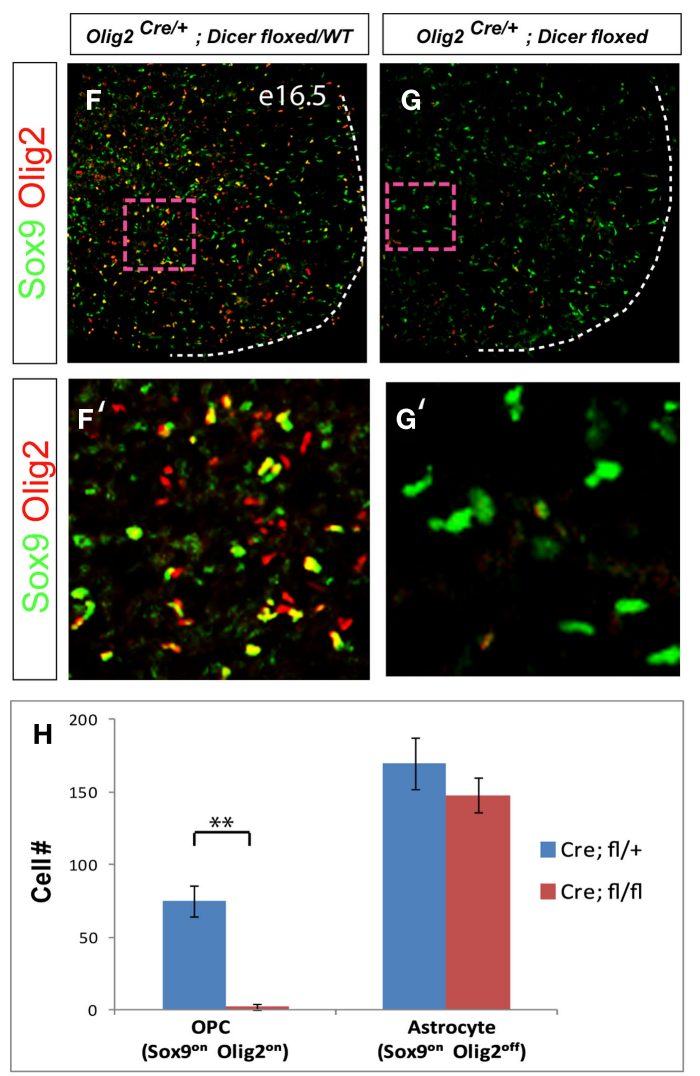

Expression of OPC (oligodendrocyte precursors) and astrocyte markers in E16.5WT and conditional KO spinal cord sections. $\left(\mathbf{F}^{\prime}, \mathbf{G}^{\prime}\right)$ Higher magnification images of areas outlined by the dashed rectangles. (H) Quantification of OPC precursors (Sox $9^{\text {on }}$, Olig2 ${ }^{\circ n}$ ) and astrocyte precursors (Sox9on, Olig2 ${ }^{\text {off }}$; number of positive cells per $15 \mu \mathrm{m}$ brachial spinal cord hemisection) in WT and conditional Dicer KO embryos, mean \pm SD reveals a decrease in the number of OPC precursors $(p<0.01)$ but no significant change in the number of astrocyte precursors. $N=3$ embryos at $\mathrm{E} 16.5$ 

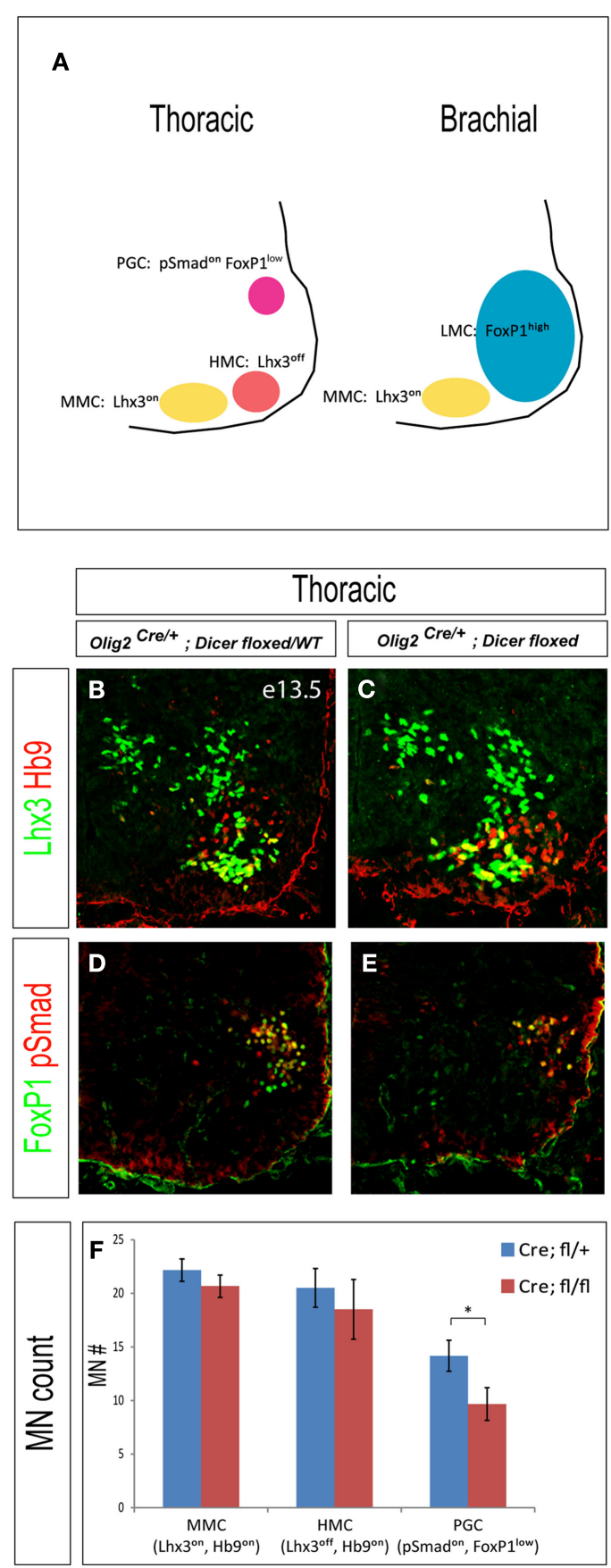

FIGURE 3 | Differential requirements of Dicer function in diverse motor neuron columnar classes. (A) Schematic diagram illustrates the anatomical arrangement of motor columns in the spinal cord (organization of lumbar and brachial spinal cord is similar). Limb innervating motor neurons are grouped in the lateral motor columns (LMCs) at brachial levels, whereas preganglionic column (PGC) motor neurons innervating sympathetic ganglia and hypaxial motor column (HMC) neurons innervating intercostal and abdominal wall muscles are located at thoracic levels. Median motor column (MMCs) neurons innervating axial muscles are present at all rostro-caudal spinal levels. (B-E) Immunostaining for pSmad and FoxP1 reveals a decrease in the number of PGC motor neurons


in the thoracic spinal cord sections of E13.5 conditional Dicer mutant

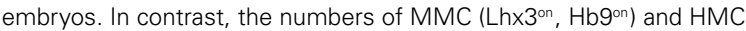
(Lhx $3^{\text {off }}$, Hb9on) motor neurons are not affected. (G-N) Immunostaining of brachial spinal cord sections reveals a decrease of LMC (FoxP1 high) motor neurons in E13.5 conditional Dicer mutant embryos, whereas MMC (LhX3 $\left.{ }^{\circ n}, \mathrm{Hb}^{\circ n}\right)$ motor neurons are not affected. $(\mathbf{F}, \mathbf{O})$ Quantification of

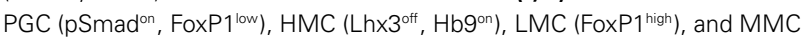
(Lhx $3^{\text {on }}, \mathrm{Hb}{ }^{\circ \text { on }}$ ) motor neurons (number of positive cells per $15 \mu \mathrm{m}$ brachial or thoracic spinal cord hemisection) in control and conditional Dicer mutant embryos, mean $\pm S D$ reveals a significant decrease in the number of PGC and LMC motor neurons ( $\left.{ }^{*} p<0.05 ;{ }^{*} p<0.01\right) . N=3$ embryos. 
column specific markers in brachial and thoracic spinal cord in E13.5 mutant embryos. Despite the normal initial production of generic motor neurons at E11.5 (Figure 2E), all examined Olig2 ${ }^{\mathrm{Cre} /+}$; Dicerflox/flox embryos exhibited a $\sim 50 \%$ decrease in the number of FoxP1 expressing LMC motor neurons innervating limb muscles at brachial levels of the spinal cord (Figure 30, $p<0.01, n=3)$. In contrast, the Lhx3 expressing MMC motor neurons innervating axial muscles were not affected $(N=3$, Figures 3G-O). This result indicates that LMC and MMC motor neurons display differential requirements for Dicer function and miRNAs.

To determine whether motor neuron subtype specification was impaired at other spinal levels we examined PGC motor neurons innervating sympathetic ganglia and HMC neurons innervating intercostal and abdominal wall musculature in the thoracic spinal cord (Figures 3B-F). We observed $\sim 30 \%$ reduction of PGC (pSmad ${ }^{\text {on }}$ and FoxP1 ${ }^{\text {low }}$ ) motor neurons in the Olig2 ${ }^{\mathrm{Cre} /+}$; Dicerflox/flox embryos, whereas HMC (Lhx3 ${ }^{\text {off }}$ and Hb9 $\left.{ }^{\text {high }}\right)$ and MMC ( $\left.\operatorname{Lhx} 3^{\text {on }}\right)$ motor neuron numbers remained unchanged compared to their heterozygous or wild type littermates $(N=3$, Figures 3B-F). These results demonstrate that specification or maintenance of LMC and PGC motor neurons depends on Dicer function.

\section{INCREASED APOPTOSIS OF LMC MOTOR NEURONS LACKING MIRNAS}

Given the decrease in the number of FoxP ${ }^{\text {on }}$ LMC neurons in the Olig2 $2^{\text {Cre/+}}$; Dicerflox/flox embryos, we considered whether this might be due to the failed induction of FoxP1 expression or due to the selective death of LMC neurons. To mark all motor neurons in the mutant and control embryos we introduced Hb9::GFP transgene (Wichterle et al., 2002) into Olig2 ${ }^{\text {Cre/+}}$; Dicer flox/flox mice. To examine whether LMC neurons might be susceptible to increased rate of apoptosis we analyzed apoptotic cells by TUNEL labeling in the mutant spinal cord on embryonic days E11.5, E13.5, and E14.5 (Figures 4A-F). We did not notice increase in TUNEL positive cells between mutant and control spinal cords on E11.5 and E13.5. By E14.5 we detected an increase in TUNEL positive cells within the LMC in mutant embryos, while no difference was observed in MMC (Figures 4E,F). Although the trend was consistent across many examined sections, the observed increase in the TUNEL labeling in LMC did not reach statistical significance, likely due to the overall small number of labeled cells. Importantly, loss of FoxP1 expressing cells was not compensated by an emergence of supernumerary FoxP1 negative motor neurons in the LMC, suggesting that LMC cells do not simply fail to express FoxP1 (Figures 5C,D). Collectively, these results indicate that the observed decrease in the number of FoxP1 positive neurons results from an increased rate of cell death in LMC.

\section{MiRNAs ARE CRITICAL FOR CORRECT EXPRESSION OF MOTOR POOL MARKERS IN LMC NEURONS}

Since not all LMC neurons are lost in Olig2 ${ }^{\mathrm{Cre} /+}$; Dicerflox/flox embryos, we asked whether remaining motor neurons acquired proper subtype identities. We examined expression of rostrocaudal determinants and motor pool subtype specific markers in the mutant spinal cord (Figure 5A). Despite the severe reduction of LMC motor neurons, the expression of appropriate set of

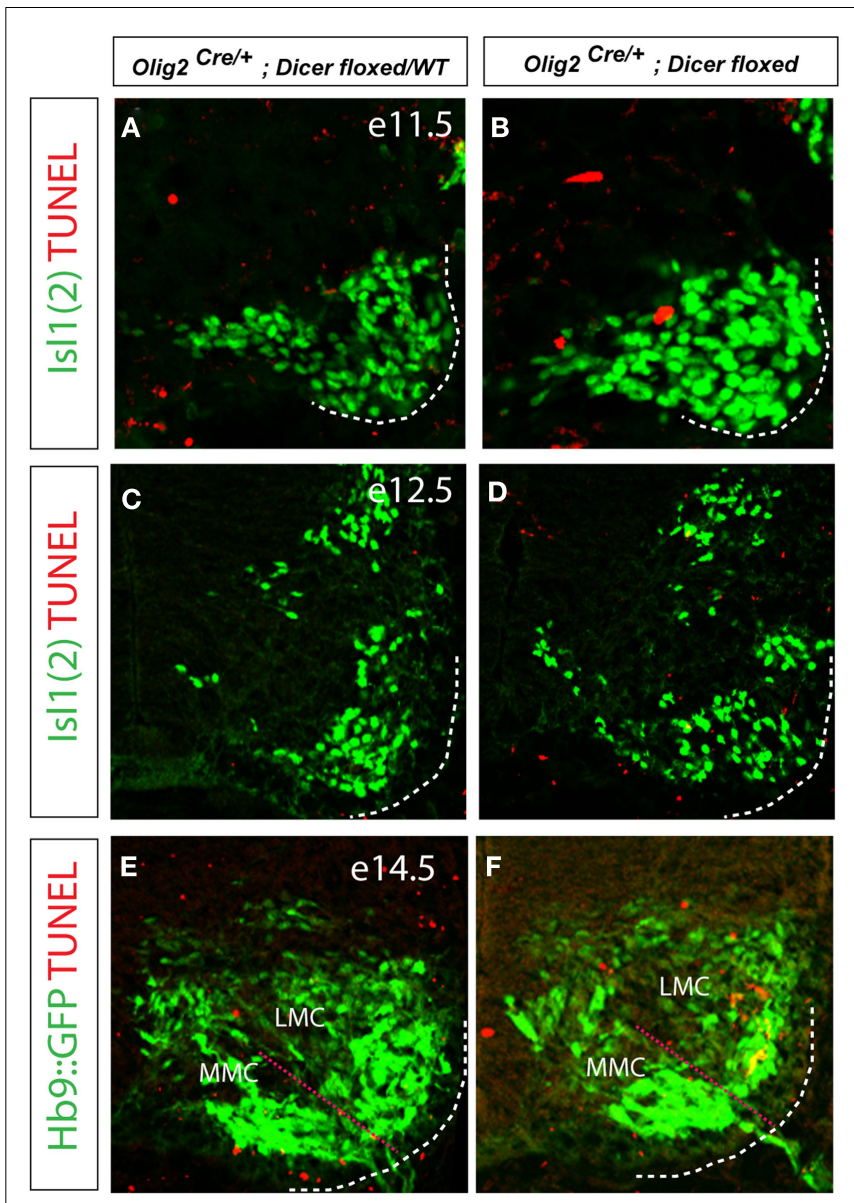

FIGURE 4 | Increased apoptosis is detected in E14.5 Dicer mutant LMC. (A-F) TUNEL labeling of fragmented apoptotic nuclei in the developing spinal cord at E11.5, 12.5, and E14.5. While the number of TUNEL positive cells in the ventral spinal cord was overall low, we observed consistently higher number of TUNEL positive nuclei within the LMC (Isl1 positive) of conditional Dicer KO embryos on day E14.5 (E,F).

brachial Hox genes was detected in the remaining LMC neurons. Hoxc $6^{\text {on }}$ brachial LMC neurons were correctly subdivided into the rostral Hoxa $5^{\text {on }}$ and caudal Hoxc $8^{\text {on }}$ LMC domain (Figures 5C-H and data not shown; Dasen et al., 2005; Jung et al., 2010), indicating that the rostro-caudal intrasegmental division of the brachial LMC is not affected in the Olig $2^{\mathrm{Cre} /+}$; Dicerflox/flox embryos.

Combinatorial Hox transcription program results in the diversification of LMC neurons into multiple motor pool identities, several of which are marked by differential expression of TFs Nkx6.1, Pea3, and Scip (Dasen and Jessell, 2009). In contrast to the normal pattern of Hox gene expression, the expression of motor pool markers was significantly eroded in mutant LMC motor neurons (Figures 5B,I-N). To determine whether the decrease in pool specific marker expression is solely due to the loss of LMC neurons we quantified the neurons expressing individual pool markers and normalized them to the total number of FoxP1 positive LMC neurons (Figure 5B). This analysis revealed that while the same fraction of LMC neurons expressed caudal brachial 

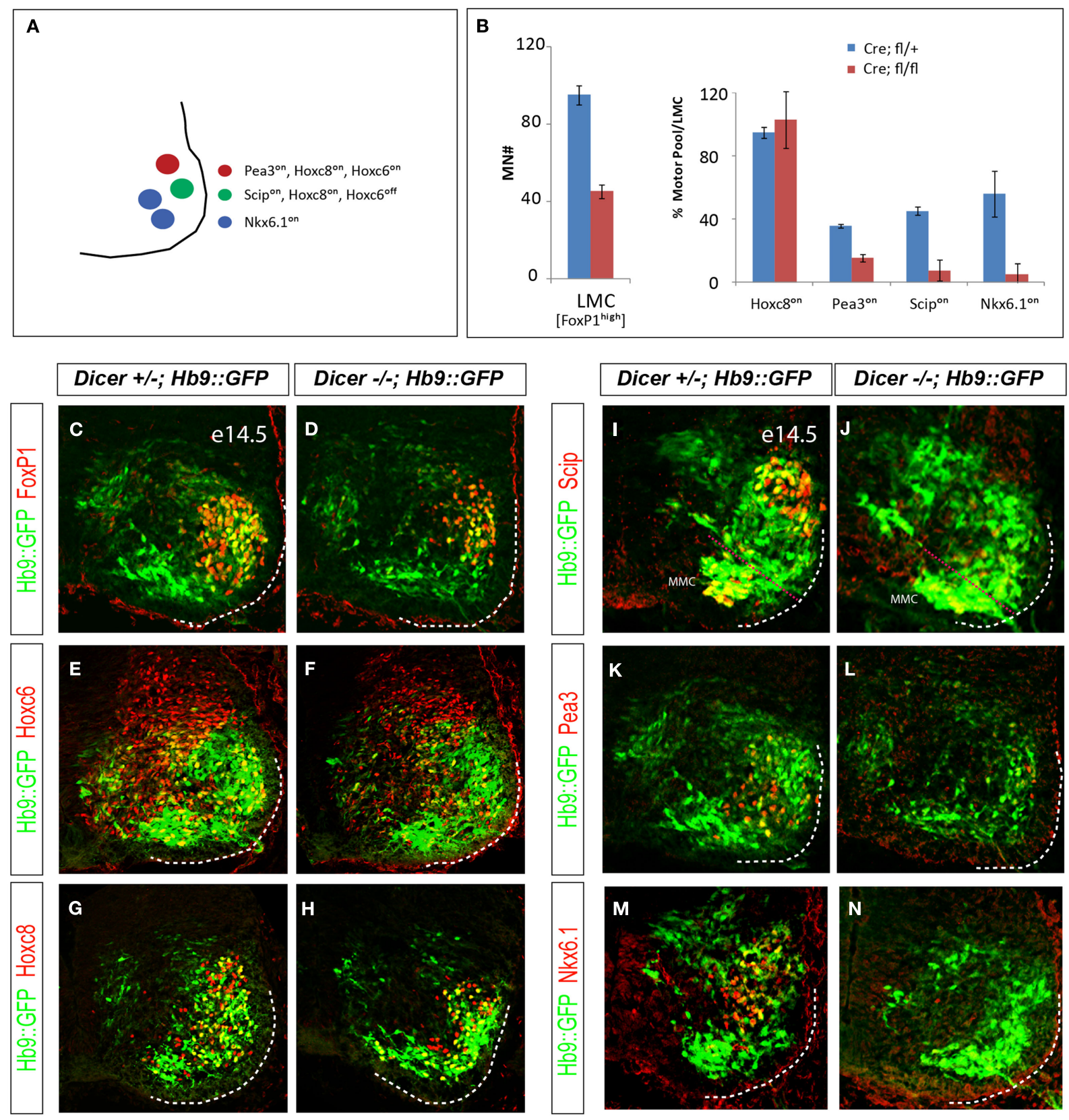

FIGURE 5 | Dicer function is necessary for proper specification of motor pool identity in the caudal brachial LMC. (A) Individual motor pools in caudal brachial $\mathrm{LMC}$ can be distinguished by the combinatorial pattern of Hoxc8, Hoxc6, Pea3, Scip, and Nkx6.1 expression. (B) Quantification of LMC (FoxP $1^{\text {high }}$ ) motor neuron numbers and the percentage LMC neurons expressing individual motor pool markers in control and conditional Dicer mutant E14.5 caudal brachial spinal cord hemisections (mean $\pm S D, N=2$ ).

(C-H) Despite the reduction of LMC (FoxP1 ${ }^{\text {high }}$ ) motor neuron number in the brachial spinal cord, the rostro-caudal patterning manifested by the expression of Hoxc6 and Hoxc8 transcription factors in the caudal brachial spinal cord is not affected in the at E14.5. Motor neurons are labeled by Hb9::GFP transgene. (I-N) The expression of all examined motor pool markers (Pea3 ${ }^{\circ}$, Scip ${ }^{\circ n}$, or Nkx6. $1^{\text {on }}$ ) is reduced in the conditional Dicer KO embryos.

marker Hoxc8, the fractions of LMC neurons expressing Pea3, Scip, and Nkx6.1 were significantly decreased. Thus, terminal differentiation of motor pools in LMC is sensitive to the loss of Dicer function, indicating that the subtype specific program requires intact miRNAs for proper execution.

\section{DISCUSSION}

Motor neuron subtype identities are defined by a hierarchical program that utilizes spatial and temporal cues to progressively diversify generic motor neurons into appropriate columnar and pool subtypes along the rostro-caudal axis of the developing spinal 


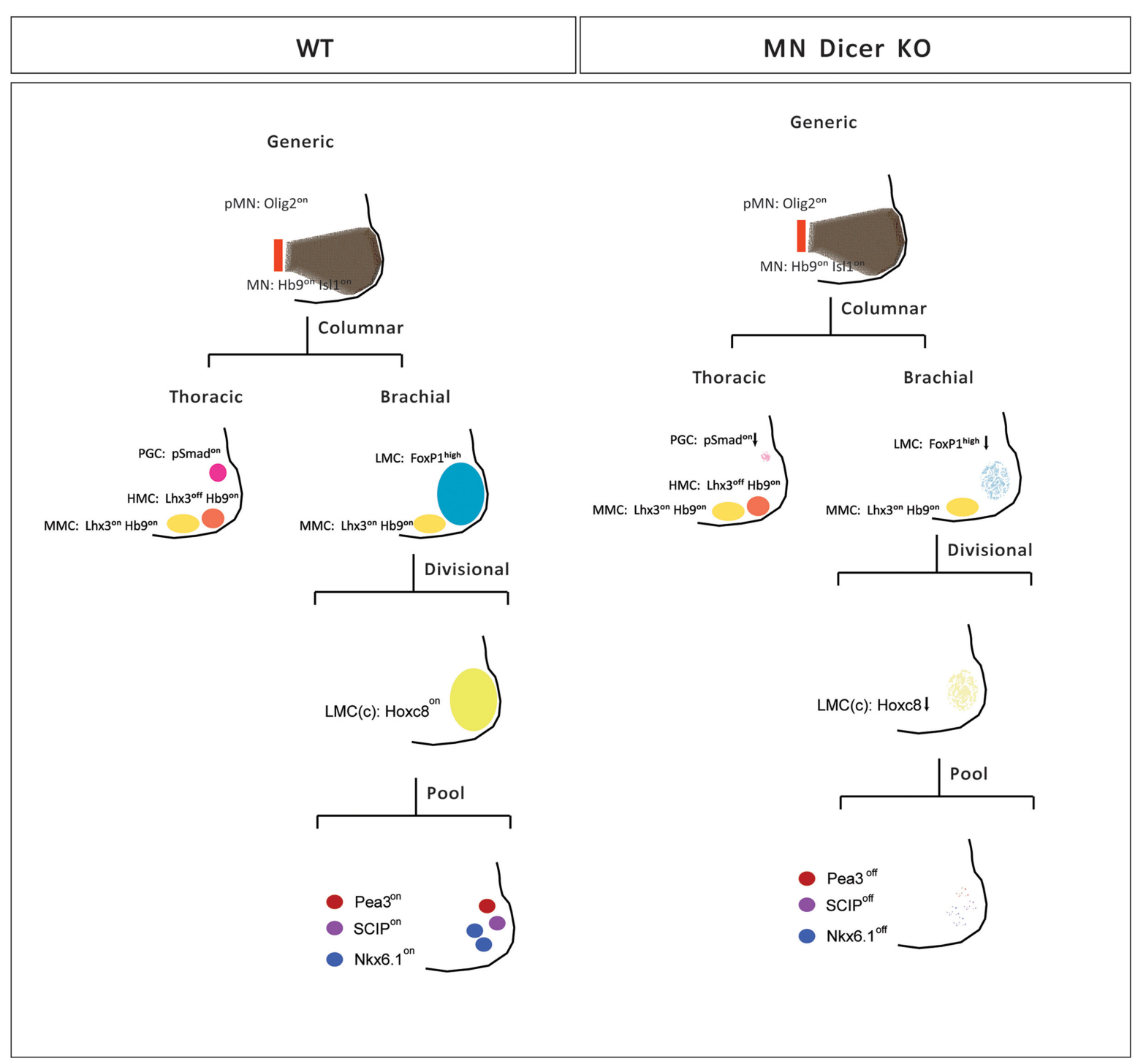

FIGURE 6 | Summary of motor neuron phenotypes in conditional Dicer KO embryos. Initial specification of pMN and nascent postmitotic generic motor neurons is not affected in conditional Dicer ${ }^{-1}$ embryos (E11.5). Subsequently, motor neurons occupying different motor columns respond differentially to the loss of Dicer activity. The numbers of PGC and LMC motor neurons are reduced whereas HMC and MMC neurons are spared in conditional Dicer ${ }^{-1}$ spinal cord (E13.5). While surviving caudal brachial LMC motor neurons in Dicer mutants express correctly Hoxc6 and Hoxc8 factors, expression of motor pool markers is significantly eroded resulting in near absence of motor neurons with defined motor pool subtype identity in E14.5 mutant caudal brachial spinal cords. cord. To determine whether posttranscriptional regulatory mechanisms contribute to the anatomically stereotypic specification of motor neuron subtypes in each segment of the developing spinal cord, we took advantage of conditional Dicer mutants in which miRNA biosynthesis is disrupted in postmitotic motor neurons. We demonstrate that Dicer/miRNAs participate in the finetuning of subtype selective motor neuron survival and motor pool identity establishment during spinal cord development (Figure 6).

\section{COMPARISON OF GENETIC MODELS DISRUPTING MIRNA BIOGENESIS IN SPINAL MOTOR NEURONS}

Previous studies have employed similar conditional Dicer knockout approach to address miRNA functions in gliogenesis
(Dugas et al., 2010; Zhao et al., 2010; Zheng et al., 2010; Table 1). Dugas et al. and Zhao et al. reported that miRNAs are essential for oligodendrocyte maturation, but not for OPC generation and astrocyte development in the brain, while Zheng et al. suggested that OPC generation and astrocyte development require Dicer functions in the developing spinal cord. Our study demonstrates that Sox9/Olig2 double positive glial progenitors are severely reduced in the mutant spinal cord, but numbers of Sox9 positive Olig2 negative glial progenitors are not changed. The discrepancy could be due to the differential developmental stage and CNS regions examined. Furthermore, different oligodendrocyte Cre divers used in the studies might give rise to differential recombination efficiencies (summarized in Table 1). Although 
Table 1 | Comparison of genetic models disrupting miRNA biogenesis in spinal motor neurons.

\begin{tabular}{|c|c|c|c|c|}
\hline & Olig2 $2^{\text {Cre/+ }}$ Dicer ${ }^{\text {flox/flox }}$ & Olig $1^{\text {Cre } /+}$ Dicer $^{\text {flox/flox }}$ & Olig $1^{\text {Cre } /+}$ Dicer $^{\text {flox/flox }}$ & Olig2 $2^{\text {Cre/+}}$ Dicer ${ }^{\text {flox/flox }}$ \\
\hline Manuscript & Dugas et al. (2010) & Zhao et al. (2010) & Zheng et al. (2010) & Chen and Wichterle (2012) \\
\hline Cre driver & Olig2 $2^{\text {tm2(TVA, cre)Rth }}$ & Olig $1^{\mathrm{tm} 1 \text { (cre)Rth }}$ & Olig $1^{\mathrm{tm} 1 \text { (cre)Rth }}$ & Olig $2^{\operatorname{tm} 1(\mathrm{cre}) T \mathrm{mj}}$ \\
\hline Gross phenotype & $\begin{array}{l}\text { Developed a notable } \\
\text { tremor from postnatal } \\
\text { day 9-10 (P9-10), yet } \\
\text { appeared to lessen with } \\
\text { age in older mice }\end{array}$ & $\begin{array}{l}\text { Born at Mendelian ratio } \\
\text { but developed severe } \\
\text { tremor and ataxia, and } \\
\text { died around postnatal } \\
\text { week } 3\end{array}$ & $\begin{array}{l}\text { Died immediately after } \\
\text { birth }\end{array}$ & $\begin{array}{l}\text { Died immediately after birth (similar to } \\
\text { Zheng et al., 2010). Probably due to } \\
\text { impairment of moving/breathing defects }\end{array}$ \\
\hline E11.5 & NA & NA & $\begin{array}{l}\text { Normal pMN patterning } \\
\text { and generic motor } \\
\text { neurons production }\end{array}$ & Same as Zheng et al. (2010) \\
\hline E13.5 & NA & NA & NA & $\begin{array}{l}\text { A robust reduction of LMC MNs in } \\
\text { brachial and mild decrease of PGC MNs at } \\
\text { thoracic segments. MMC and HMC } \\
\text { neurons are not changed }\end{array}$ \\
\hline E14.5 & NA & NA & NA & $\begin{array}{l}\text { LMC pool markers including Pea3, Scip, } \\
\text { Nkx6.1 are mostly disappeared with } \\
\text { concomitant increase of apoptosis }\end{array}$ \\
\hline E16.5 18.5 & NA & NA & $\begin{array}{l}\text { Absent of OPC } \\
\text { precursors and lost } \\
\text { astrocyte near floor } \\
\text { plate }\end{array}$ & $\begin{array}{l}\text { A majority of OPC precursors are lost, } \\
\text { while astroglia appear normal (consistent } \\
\text { to Dugas et al., 2010; Zhao et al., } 2010 \text { but } \\
\text { different to Zheng et al., 2010) }\end{array}$ \\
\hline
\end{tabular}

Olig2 $2^{\text {tm2(TVA,cre)Rth }}$; Dicerflox/flox mice display a notable tremor phenotype from postnatal day $9-10$, more than $50 \%$ of oligodendrocytes are generated and recovered at older stage (Dugas et al., 2010). This phenotype contrasts with the postnatal lethality of Olig $2^{\mathrm{Cre} /+}$; Dicer flox/flox mice examined in this study, indicative of more efficient and complete deletion of Dicer function in motor neuron and oligodendroglial lineages (Dessaud et al., 2007, 2010; Chen et al., 2011).

Consistent with the results of Zheng et al., we did not observe an overt ventral pattering defect or a decrease in the generic postmitotic motor neuron production at E11.5. This is not surprising, given that it takes $3 \sim 4$ days to deplete existing miRNA reservoir in the cells following the conditional inactivation of the Dicer function (Chen et al., 2011). Therefore Olig2 ${ }^{C r e /+}$ recombination should not significantly affect miRNA function in motor neuron progenitors, resulting in the normal patterning and generic motor neuron production in the conditional Dicer mutant embryos.

\section{AUTONOMOUS VS. NON-CELL AUTONOMOUS PHENOTYPES AND MECHANISM OF DICER FUNCTION}

Previous study has shown that inactivation of Dicer in the astroglial lineage results in non-cell autonomous neuronal degeneration (Tao et al., 2011), raising the question whether some of the observed phenotypes might be due to non-cell autonomous effects. We think this is unlikely because Olig2 ${ }^{C r e /+}$ mediated deletion of Dicer function did not markedly affect astroglial progenitors (Sox $9^{\text {on }}$; Olig2 $2^{\text {off }}$ ), and the observed motor neuron phenotypes preceded the wave of oligodendrocyte and astrocyte production. However, future studies targeting Dicer function in spinal glial compartment are needed to formally exclude the possibility of non-cell autonomous contribution to the observed motor neuron defects.

Dicer participates in a broad spectrum of biological processes, including miRNA biogenesis, heterochromatin maintenance, and fragmentation of chromosomal DNA during apoptosis (Nakagawa et al., 2010; Cernilogar et al., 2011). Although pro-apoptotic role of Dicer enzyme is inconsistent with the observed increase in motor neuron loss in conditional Dicer embryos, follow-up studies targeting specific microRNAs in the developing spinal cord are needed to understand the motor neuron defects on a mechanistic level.

\section{SELECTIVE REQUIREMENT FOR DICER FUNCTION IN MOTOR NEURON SUBTYPES}

Our study revealed that Dicer function requirements are motor neuron subtype specific. Brachial LMC and thoracic PGC display strong reliance on Dicer function, whereas MMC present in all spinal cord segments are relatively spared in the conditional Dicer mutants (Figure 6). The subtype specificity of motor neuron loss is unlikely due to a differential efficiency of Dicer deletion in MMC vs. LMC neurons, as both motor columns exhibit comparable degree of $\mathrm{Olig} 2^{\mathrm{Cre} /+}$ driven recombination. Instead we suggest that the differences in motor neuron survival might reflect motor neuron subtype specific differences in the expression of miRNAs 
or their targets, or differential susceptibility of individual motor neuron subtypes to degeneration.

It is of interest that both affected populations of motor neurons in our study express FoxP1 TF (high level in LMC and low level in PGC). Recently it has been shown that mir-9 is critical for fine-tuning of FoxP1 expression levels in the chick spinal cord (Otaegi et al., 2011a,b). Knock-down of mir-9 alone is sufficient to increase FoxP1 expression levels and promote specification of PGC or LMC motor neurons. In contrast, our study revealed selective loss of LMC and PGC neurons, pointing to a more complex role of Dicer function in motor neuron specification and survival.

Despite the reduction of LMC motor neurons in the conditional Dicer mutants, the rostro-caudal (Hoxa5 ${ }^{\text {on }}$ and Hoxc $8^{\text {on }}$ ) division of LMC remains patterned normally. However, the expression of motor neuron pool markers (Pea3, Scip, and Nkx6.1) was severely disrupted in the mutants. This suggests that besides their role in the regulation of LMC cell death, miRNA function is also important for proper motor pool specification and maturation. Our data do not establish whether the failure to properly specify motor pool identity is the primary defect, leading to the LMC

\section{REFERENCES}

Briscoe, J., Pierani, A., Jessell, T. M., and Ericson, J. (2000). A homeodomain protein code specifies progenitor cell identity and neuronal fate in the ventral neural tube. Cell 101, 435-445.

Cao, X., Pfaff, S. L., and Gage, F. H. (2007). A functional study of miR124 in the developing neural tube. Genes Dev. 21, 531-536.

Cernilogar, F. M., Onorati, M. C., Kothe, G. O., Burroughs, A. M., Parsi, K. M., Breiling, A., Lo Sardo, F., Saxena, A., Miyoshi, K., Siomi, H., Siomi, M. C., Carninci, P., Gilmour, D. S., Corona, D. F., and Orlando, V. (2011). Chromatinassociated RNA interference components contribute to transcriptional regulation in Drosophila. Nature 480, 391-395.

Chen, J. A., Chu, S. T., and Amaya, E. (2007). Maintenance of motor neuron progenitors in Xenopus requires a novel localized cyclin. EMBO Rep. 8, 287-292.

Chen, J. A., Huang, Y. P., Mazzoni, E. O., Tan, G. C., Zavadil, J., and Wichterle, H. (2011). Mir-17-3p controls spinal neural progenitor patterning by regulating Olig2/Irx3 cross-repressive loop. Neuron 69, 721-735.

Chen, J. A., Voigt, J., Gilchrist, M., Papalopulu, N., and Amaya, E. (2005). Identification of novel genes affecting mesoderm formation and morphogenesis through an enhanced large scale functional screen in Xenopus. Mech. Dev. 122, 307-331.
Chen, J. A., and Wichterle, H. (2012). Apoptosis of limb innervating motor neurons and erosion of motor pool identity upon lineage specific Dicer inactivation. Front. Neurosci. 6:69. doi:10.3389/fnins.2012.00069

Dasen, J. S. (2009). Transcriptional networks in the early development of sensory-motor circuits. Curr. Top. Dev. Biol. 87, 119-148.

Dasen, J. S., De Camilli, A., Wang, B., Tucker, P. W., and Jessell, T. M. (2008). Hox repertoires for motor neuron diversity and connectivity gated by a single accessory factor, FoxP1. Cell 134, 304-316.

Dasen, J. S., and Jessell, T. M. (2009). Hox networks and the origins of motor neuron diversity. Curr. Top. Dev. Biol. 88, 169-200.

Dasen, J. S., Liu, J. P., and Jessell, T. M. (2003). Motor neuron columnar fate imposed by sequential phases of Hox-c activity. Nature 425 , 926-933.

Dasen, J. S., Tice, B. C., Brenner-Morton, S., and Jessell, T. M. (2005). A Hox regulatory network establishes motor neuron pool identity and target-muscle connectivity. Cell 123, 477-491.

Dessaud, E., Ribes, V., Balaskas, N., Yang, L. L., Pierani, A., Kicheva, A., Novitch, B. G., Briscoe, J., and Sasai, N. (2010). Dynamic assignment and maintenance of positional identity in the ventral neural tube by the morphogen sonic hedgehog. PLoS Biol. 8, e1000382. doi:10.1371/journal.pbio. 1000382

neuron cell death. We think this is unlikely, as a complete failure to specify LMC pool identity in FoxP1 mutant animals results only in a $\sim 15-30 \%$ decrease in motor neuron numbers (Dasen et al., 2008; Surmeli et al., 2011), while conditional Dicer mutant animals exhibit a $\sim 50 \%$ loss of LMC neurons. Finally, once subtype specific markers for MMC and HMC neurons are identified, it will be of interest to examine whether diversification of non-LMC neurons is also dependent on Dicer function.

Motor neuron subtype specific degeneration has been described in several motor neuron degenerative diseases (Kanning et al., 2010). Our observation that a subset of LMC neurons degenerate in the Dicer null animals raises the possibility that the molecular mechanism underlying increase sensitivity of LMC and PGC motor neurons in the Dicer mutant mice might be implicated in motor neuron pathologies.

\section{ACKNOWLEDGMENTS}

We thank Ben Novitch (UCLA) for sharing Olig2 ${ }^{\mathrm{Cre} /+}$ mice. Tom Jessell, Fiona Doetsch, Ed Laufer (Columbia), and Jeremy Dasen (NYU) for reagents and antibodies. This research was supported by NIH grants NS058502 and NS055923.

Dessaud, E., Yang, L. L., Hill, K., Cox, B., Ulloa, F., Ribeiro, A., Mynett, A., Novitch, B. G., and Briscoe, J. (2007). Interpretation of the sonic hedgehog morphogen gradient by a temporal adaptation mechanism. Nature 450 , 717-720.

Dugas, J. C., Cuellar, T. L., Scholze, A., Ason, B., Ibrahim, A., Emery, B., Zamanian, J. L., Foo, L. C., Mcmanus, M. T., and Barres, B. A. (2010). Dicer1 and miR-219 are required for normal oligodendrocyte differentiation and myelination. Neuron 65, 597-611.

Harfe, B. D., Mcmanus, M. T., Mansfield, J. H., Hornstein, E., and Tabin, C. J. (2005). The RNaseIII enzyme Dicer is required for morphogenesis but not patterning of the vertebrate limb. Proc. Natl. Acad. Sci. U.S.A. 102, 10898-10903.

Jung, H., Lacombe, J., Mazzoni, E. O., Liem, K. F. Jr., Grinstein, J. Mahony, S., Mukhopadhyay, D., Gifford, D. K., Young, R. A., Anderson, K. V., Wichterle, H., and Dasen, J. S. (2010). Global control of motor neuron topography mediated by the repressive actions of a single hox gene. Neuron 67, 781-796.

Kanning, K. C., Kaplan, A., and Henderson, C. E. (2010). Motor neuron diversity in development and disease. Annu. Rev. Neurosci. 33, 409-440.

Masahira, N., Takebayashi, H., Ono, K., Watanabe, K., Ding, L., Furusho, M., Ogawa, Y., Nabeshima, Y., Alvarez-Buylla, A., Shimizu, K., and
Ikenaka, K. (2006). Olig2-positive progenitors in the embryonic spinal cord give rise not only to motoneurons and oligodendrocytes, but also to a subset of astrocytes and ependymal cells. Dev. Biol. 293, 358-369.

Nakagawa, A., Shi, Y., Kage-Nakadai, E., Mitani, S., and Xue, D. (2010). Caspase-dependent conversion of Dicer ribonuclease into a death-promoting deoxyribonuclease. Science 328, 327-334.

Otaegi, G., Pollock, A., Hong, J., and Sun, T. (2011a). MicroRNA miR-9 modifies motor neuron columns by a tuning regulation of FoxP1 levels in developing spinal cords. J. Neurosci. 31, 809-818.

Otaegi, G., Pollock, A., and Sun, T. (2011b). An optimized sponge for microRNA miR-9 affects spinal motor neuron development in vivo. Front. Neurosci. 5:146. doi:10.3389/fnins.2011.00146

Rousso, D. L., Gaber, Z. B., Wellik, D., Morrisey, E. E., and Novitch B. G. (2008). Coordinated actions of the forkhead protein Foxpl and Hox proteins in the columnar organization of spinal motor neurons. Neuron 59, 226-240.

Srinivas, S., Watanabe, T., Lin, C. S., William, C. M., Tanabe, Y., Jessell, T. M., and Costantini, F. (2001). Cre reporter strains produced by targeted insertion of EYFP and ECFP into the ROSA26 locus. BMC Dev. Biol. 1, 4. 
Surmeli, G., Akay, T., Ippolito, G. C., Tucker, P. W., and Jessell, T. M. (2011). Patterns of spinal sensorymotor connectivity prescribed by a dorsoventral positional template. Cell 147, 653-665.

Tao, J., Wu, H., Lin, Q., Wei, W., Lu, X. H., Cantle, J. P., Ao, Y., Olsen, R. W., Yang, X. W., Mody, I., Sofroniew, M. V., and Sun, Y. E. (2011). Deletion of astroglial Dicer causes non-cellautonomous neuronal dysfunction and degeneration. J. Neurosci. 31, 8306-8319.

Visvanathan, J., Lee, S., Lee, B., Lee, J. W., and Lee, S. K. (2007). The microRNA miR-124 antagonizes the anti-neural REST/SCP1 pathway during embryonic CNS development. Genes Dev. 21, 744-749.

Wichterle, H., Lieberam, I., Porter, J. A., and Jessell, T. M. (2002). Directed differentiation of embryonic stem cells into motor neurons. Cell 110, 385-397.

Zhao, X., He, X., Han, X., Yu, Y., Ye, F., Chen, Y., Hoang, T., Xu, X., Mi, Q. S., Xin, M., Wang, F., Appel, B., and $\mathrm{Lu}, \mathrm{Q}$. R. (2010). MicroRNAmediated control of oligodendrocyte differentiation. Neuron 65, 612-626.

Zheng, K., Li, H., Zhu, Y., Zhu, Q., and Qiu, M. (2010). MicroRNAs are essential for the developmental switch from neurogenesis to gliogenesis in the developing spinal cord. J. Neurosci. 30, 8245-8250.

Conflict of Interest Statement: The authors declare that the research was conducted in the absence of any commercial or financial relationships that could be construed as a potential conflict of interest.

Received: 07 February 2012; accepted: 25 April 2012; published online: 17 May 2012.
Citation: Chen J-A and Wichterle $H$ (2012) Apoptosis of limb innervating motor neurons and erosion of motor pool identity upon lineage specific Dicer inactivation. Front. Neurosci. 6:69. doi: 10.3389/fnins.2012.00069

This article was submitted to Frontiers in Neurogenesis, a specialty of Frontiers in Neuroscience.

Copyright $\odot 2012$ Chen and Wichterle. This is an open-access article distributed under the terms of the Creative Commons Attribution Non Commercial License, which permits non-commercial use, distribution, and reproduction in other forums, provided the original authors and source are credited. 